\title{
Research on Theory, Connotation and Evaluation System of State Owned Enterprises' Innovative Vitality
}

\author{
_A Case on National Power Grid Corp \\ Zhang Hualei ${ }^{1, \mathrm{a}, *}$, Wang Zhiyi ${ }^{2, \mathrm{~b}}$, Chang Yan ${ }^{1, \mathrm{c}}$, Tian Xiaofeng ${ }^{2, \mathrm{~d}}$ \\ ${ }^{1}$ System Reform Office of State Grid Corporation of China \\ ${ }^{2}$ State Grid Energy Research Institute Co., Ltd \\ a zhanghualei@sgeri.sgcc.com.cn, ${ }^{\mathrm{b}}$ zhiyi-wang@sgcc.com.cn, \\ b changyan@sgeri.sgcc.com.cn, ${ }^{\mathrm{d} x i a o f e n g-t i a n @ s g c c . c o m . c n, ~}$
}

Keyword: State-owned enterprise, Vitality, Theory and connotation, Evaluation system

\begin{abstract}
At present, the state-owned enterprises' (SOE) mechanism of the management system hase been continuously optimizationed and the ability of independent innovation has been continuously strengthened, how to effectively stimulate the innovative vitality of state-owned enterprises has become the focus of research among enterprises. On the basis of relevant theories, The paper makes an in-depth study of the new situation faced by state-owned enterprises. By constructing the evaluation index system of enterprise group innovation vitality, the paper provide research support for comprehensively enhancing the vitality of state-owned groups.
\end{abstract}

\section{Introduction}

With the increasing uncertainty of business environment and the continuous emergence of new technological means, state-owned enterprises have entered a new era. Doing stronger, better and bigger become the foothold for the development of state-owned enterprises in the new era.

But, some outstanding problems still need to be solved, such as short of state-owned capital's authorized management system, the low proportion of marketing candidates and the lack of incentives for scientific and technological innovation personnel. The above problems of the state-owned enterprises are mainly manifested in the poor mechanism, low efficiency, less innovation and weak vitality. Therefore, the key to promoting the state-owned enterprises to do stronger, better and bigger is to strengthen the position of the enterprise market through scientific and technological innovation, institutional mechanism optimization and business model innovation, to stimulate and release the vitality and creativity of the employees, and to form a sustainable competitive advantage.

\section{The correlation theory of enterprise vitality}

Enterprise vitality presents a benign cycle of self development in market competition. The enterprise, as a commodity producer and operator with independent management and self profit and loss, follows the requirements of the objective economic law, give full play to the enthusiasm, initiative and creativity of the business operators and employees in the process of production and operation, through the interaction of the quality of the enterprise and the external environment. Through the analysis of domestic research, it is found that the theory of enterprise vitality mainly includes several aspects, which includes Ability Theory, Life Theory, Function Theory, State Theory, Mechanism Theory, External Theory, Internal Theory, Benefit Theory.

\section{The research on the evaluation model of innovation vitality of company group}

The characteristics of the National Power Grid Corp are not only to ensure the overall safety and efficiency of the power grid operation, but also to keep close to customers, improve service 
efficiency and customer satisfaction. The integrity of the group's innovation vitality is stronger. It can comprehensively measure the innovation vitality of the company group and optimize the allocation capability and efficiency of core resources such as human property, technology, data and so on, to achieve the goal of "organizational" vitality.

In order to give full play to the leading role of the company in the innovation driven development and activity promotion of the central enterprise, to stimulate the innovation vitality of the company, we need to fully use and give full play to the guiding and stimulating functions of the evaluation of innovative vitality. Therefore, on the basis of comprehensive consideration the starting point of the company's vitality evaluation and the internal characteristics of the evaluation index system construction, the research group proposed the overall goal of building the evaluation model of innovation vitality, that is, establish a set of index system and evaluation model to scientific and objective evaluation results, significant guiding effect of the company's innovation vitality.

\section{The construction of the innovation vitality index system of the company group}

Under the framework of the current management architecture and supervision system of the company, we elaborate on the two levels from the angle of organization and the human. The two levels constitute the index system of innovation vitality of the company group.

From the perspective of organization, innovation vitality includes innovation performance, synergy efficiency, resource allocation flexibility and innovation culture.

The so-called innovation performance refers to the enterprise around its own development goals, using scientific and technological resources to create new scientific research results, and translate into internal conditions and external manifestations of the actual productivity of the enterprise, it including innovation resources input ability, innovation management ability, innovation realization ability and so on.

Synergistic benefit refers to the improvement of management and the increase of benefits from the following three transformations, that is, the transformation from the fragmentation to the cooperative operation, the transformation from the resource dispersion to the optimal allocation, and the transition from the extensive management to the lean operation.

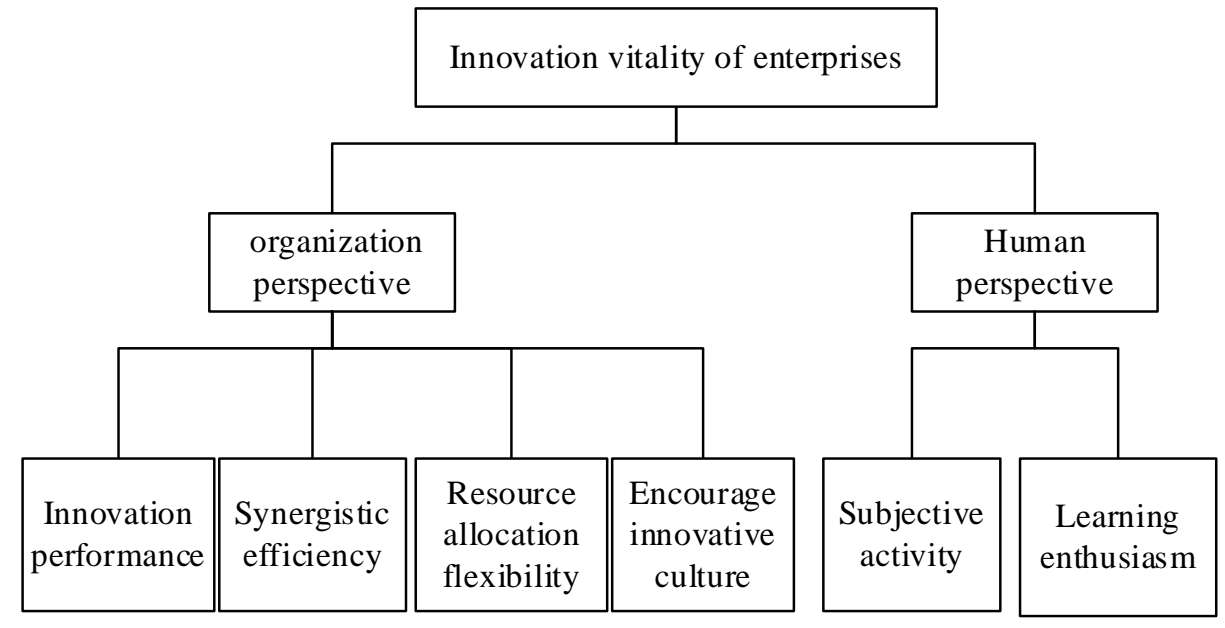

Fig 1 The framework of innovation vitality index of enterprise group

Resource allocation flexibility is a dynamic alliance built on the basis of following the principle of voluntary allocation. It is beneficial to improve the utilization of various kinds of resources and to rationally configure the internal resources of the enterprise. It mainly includes the allocation of resources, especially the core resources, and the operation of internal resources.

Encouraging the innovation culture is to establish excellent enterprise culture to promote the harmonious development of the enterprise and to promote the successful implementation of the 
enterprise's strategic goal through the means of cultural integration and cultural attraction.

From the perspective of personnel, innovation vitality includes People's subjective initiative and learning enthusiasm.

From the individual level, innovation vitality can be evaluated from the perspectives of employee emotion, employee capability and employee performance.

Confusion, fear, dissatisfaction, wait-and-see, selfishness, nostalgia, comparisons, nostalgia and other emotions may lead to employees' lack of vitality.

The positive manifestations of employee vitality are organizational coordination, communication skills, leadership, learning ability, adaptability and innovation ability.

The final results of employee vitality are embodied in employee performance, including work efficiency, work effect, production safety effect, attendance rate, control or improvement of related technology / quality, and number of patent development.

\section{The key point of optimizing the innovation vitality of the company group}

\subsection{Optimizing the organization and management system at the headquarters level}

Based on business process reengineering, optimize the organization structure. On the one hand, to improve the strategic understanding of business process reengineering, in the framework of the new era strategic system of the company, to accelerate the study of business process change up to the "Top Leader" project. On the other hand, it is suggested that the company set up a leadership group for business process change, and the "Top Leader" work as the leader of the leading group. At the same time, the leadership group office is set up. The director of the leadership group office is also the director of the corporate system reform office, which is responsible for the implementation of the change of the business process. Finally, on the basis of business process transformation, we will take the lead in promoting the dynamic adjustment of headquarters departments and improving the efficiency of headquarters operation.

To optimize the scope of responsibilities of the Department, reduce interdepartmental functions, promote the integration of relevant posts in the headquarters department, to achieve streamlined and efficient management of headquarters and to control "big business diseases" from the source.

\subsection{Increase the flexibility of the management and control of the company group}

The implementation of classification authorization, increase the authorization to grass-roots level. Establish a reasonable authorization mechanism, appropriately enhance the company's autonomy, stimulate grassroots vitality, respond quickly to the market and promote the emerging market business to pilot operation. The flexible management and control mechanism should be based on reasonable authorization, in order to improve the autonomy and flexibility of management and control, by appropriately increasing the autonomy of investment (project construction, capital allocation), material procurement, and selecting and employing persons, rationally arranging the company's self-control funds, self investment projects, and moderately relaxing progress control, to increase the company's market response speed and enhance the company's business vitality.

\subsection{Perfecting the layout of scientific and technological innovation and integrating scientific and technological innovation resources}

\subsubsection{Building a scientific and effective system of scientific and technological innovation.}

Optimize and integrate the innovation resources, make clear the position of the main function of the innovation, and get through the complete innovation chain covering basic forward-looking research, key technology research and development, application technology and product development, and the application of results, realize the close coupling of scientific research and industry, scientific research and production, scientific research and the development of the company, improve the innovation ability of the company, to built the world - class experimental research system. 


\subsubsection{To build a contingent of innovative scientific research talents.}

To condense and cultivate academic leaders and technical backbone with outstanding level and innovative ability, actively participate in the implementation of the "Millennium Project" and set up a scientific and technological team. We must adhere to technological innovation as the foundation, take management innovation as a synergy, take business innovation as the way, and take cultural innovation as the guarantee.

\subsection{Adjust and optimize the grass-roots management system, increase the ability of self-management and control at the grassroots level}

We should revise and improve the grass-roots management system and establish a management system that meets customer requirements and market competition. According to the relevant regulations of the relevant national Power Grid Corp system and the current market, environment, policy and other external factors, combined with the industry characteristics and business characteristics of the power grid enterprises, publishing and revising various regulations to build a set of management system with management standard, high efficiency, fine to grass root, so as to achieve the win-win of the high efficiency and basic level self control.

\subsection{Improve the incentive and restraint mechanism, and promote "attrition, efficiency and salary increase"}

By establishing a linkage mechanism between total wages and performance, the total wage can be increased or reduced. Make clear the linear relationship between the total salary and the operating performance, form the salary distribution mechanism adapted to the business development, and scientifically determine the wage increment of each business and each block, and establish the increase mechanism of the total wage growth based on the incremental benefit oriented.

To the grass-roots units and responsible people, the establishment four orientated assessment mechanism of innovation, reduction, efficiency, activation, to strengthen the close hook of assessment results and compensation incentive.

\subsection{Perfecting the system of scientific and technological innovation}

On the one hand, build a grass-roots innovation platform to provide the support of talent, equipment, field, technology, sharing, popularization and application, guide the staff to combine the enterprise with the development of the company, and build a technical innovation ecosystem for the employees of the company.

On the other hand, we have set up a platform for sharing and transforming scientific and technological achievements, perfect transformation of scientific and technological achievements support service system, and building a specialized and marketable national technology trading platform based on online and offline integration.

\subsection{Building an innovative enterprise culture}

The construction of innovative enterprise culture as an important measure to lead the development of enterprises, to agglomerate the will of employees and to improve the "soft strength" of the enterprise, make the enterprise and employees form a "destiny community", and stimulate the spirit power of all the employees to strive to go up and do business.

The first is to promote innovative culture, to promote innovative culture of enterprise and to hold "business competition" and other innovative activities to further cultivate the innovative ideas of respect knowledge, creation, pursuit of excellence and the participation of everyone, and to stimulate the entrepreneurial innovation enthusiasm of the employees, especially the young employees, and expand the space of innovation and entrepreneurship. The two is to mould the trial and error mechanism and fault tolerance culture, to tolerate the setbacks and mistakes in the process of innovation, to form a continuous improvement in trial and error, and to examine, reflect and amend the cultural atmosphere in the exploration and practice. Through the establishment of an 
innovative corporate culture, attracting more talents to join, to provide grass-roots innovation activities to provide cultural and environmental protection.

\section{Acknowledgements}

The subject is funded by the national Power Grid Corp science and technology project-“The key technology research on "three sets and the five major" system consolidates and promotes under the new situation of reform and the new technology conditions"

\section{References}

[1] S. Djankov, R. L.Porte \& F.Lopped Silages et al. The Regulation of Entry.(2002)Quarterly Journal of Economics,117 ( 01) : 10-17.

[2] Megginson. W. L, Netter. From state to market: a survey of empirical studies on privatization. (2001) Journal of economic literature, 39(2):321-389.

[3] Shleifera, Vishny RW. The Grabbing Hand: Government Pathologies and Their Cures. (2001)Cambridge: Harvard University Press,1998,23(3):301-348.

[4] Shleifera, Vishny RW.A survey of corporate government. (2001)Journal of finance. 1997, 52(2): 737-783.

[5] Jianping Deng, Yong Zeng, Jia He. Shareholding reform of state-owned enterprises and control.(2001)Frontiers of Business Research in China.2010,4(2):185-208.

[6] Fox Z. Y. Hu, George C. S.Lin. Situating regional advantage in geographical political economy: Transformation of the state-owned enterprises in Guangzhou, China. (2001)Geoforum, 2011, 42(6): 696-707. 